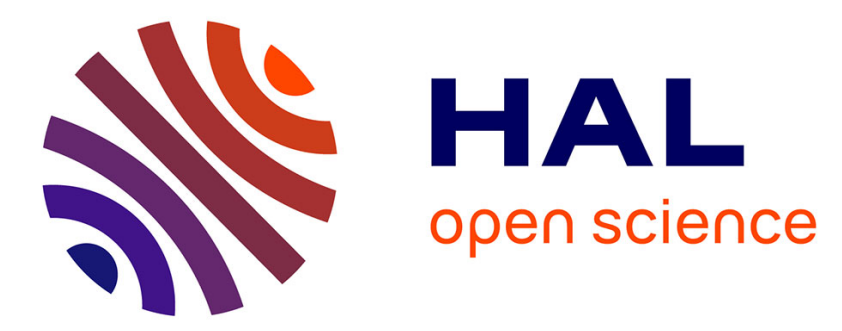

\title{
Load-dependent Friction Laws of Three Models of Harmonic Drive Gearboxes Identified by Using a Force Transfer Diagram
}

\author{
Carlos Wilfrido Ponce Quiroga, Gabriel Abba, Jean-Francois Antoine, \\ Thibaut Raharijaona, Philippe Garrec
}

\section{To cite this version:}

Carlos Wilfrido Ponce Quiroga, Gabriel Abba, Jean-Francois Antoine, Thibaut Raharijaona, Philippe Garrec. Load-dependent Friction Laws of Three Models of Harmonic Drive Gearboxes Identified by Using a Force Transfer Diagram. 12th International Conference on Mechanical and Aerospace Engineering, Jul 2021, Athens (on line), Greece. hal-03292998

\section{HAL Id: hal-03292998 https://hal.science/hal-03292998}

Submitted on 20 Jul 2021

HAL is a multi-disciplinary open access archive for the deposit and dissemination of scientific research documents, whether they are published or not. The documents may come from teaching and research institutions in France or abroad, or from public or private research centers.
L'archive ouverte pluridisciplinaire $\mathbf{H A L}$, est destinée au dépôt et à la diffusion de documents scientifiques de niveau recherche, publiés ou non, émanant des établissements d'enseignement et de recherche français ou étrangers, des laboratoires publics ou privés. 


\section{Load-dependent Friction Laws of Three Models of Harmonic Drive Gearboxes Identified by Using a Force Transfer Diagram}

\author{
PONCE QUIROGA Carlos Wilfrido, ABBA \\ Gabriel, ANTOINE Jean-Francois, \\ RAHARIJAONA Thibaut \\ LCFC \\ Université de Lorraine, Arts et Métiers, HESAM \\ Université, F-57070 Metz, France \\ e-mail: \{carlos-wilfrido.ponce-quiroga, gabriel.abba, \\ jean-francois.antoine, thibaut.raharijaona\}@univ- \\ lorraine.fr
}

\author{
GARREC Philippe \\ Interactive Robotics Unit \\ CEA LIST \\ Palaiseau, France \\ e-mail: philippe.garrec@cea.fr
}

\begin{abstract}
Industrial robotics and aerospace engineering widely use harmonic drive gearboxes for their reliability, high accuracy with zero backlash and high ratio torque transmission However, they present known problematic behaviors that affect their performance. The article deals with the first step towards the improvement of torque control of collaborative robots. We designed and developed two experimental setups to study three types of Harmonic Drive gearboxes. We identify the friction laws by using Force Transfer Diagrams. The results exhibit a new parabolic law of friction torque as a function of the transmitted torque.
\end{abstract}

Keywords-harmonic drive; friction; torque; force Transfer diagram; collaborative robots

\section{INTRODUCTION}

Harmonic Drive (HD) gearbox is widely applied in robotics and aerospace because of its compact and lightweight structure, high ratio, coaxial input-output shafts, hollow shaft possibility and its negligible backlash [1]. However, several drawbacks have been identified. Friction being one of them [2] has been identified as the responsible for most of the energy loss [3]. Hence, here we will concentrate only on the friction torque aspect at low speed, primarily for the purpose of applications in collaborative and light weight robotic manipulators where HD are widely used.

The context of the study is the linearization of torque transfer in HD gearboxes in order to improve their torque control. In collaborative robots the accuracy of torque control is especially important at low speed. Thus, we will focus only on the dependence of friction torque at low speed and its compensation.

We show that the friction torque versus the load is nonlinear contrary to a spur gear or a ball-screw. We found that a parabolic law models the friction torque at low speed over a torque domain limited by what the constructor names "repeatable peak torque". We identified both the DIRECT and INDIRECT (motoring and regenerating) friction torque laws by plotting a Force Transfer Diagram (FTD). We found the parabolic shape for three models of HD gearboxes: (i) “cup” flexspline, (ii) mushroom flexspline, (ii) differential flexspline, suggesting that this behavior is a consequence of a common mechanical process involved.

The paper is organized as follows: Section II presents an overview of the HD; section III, the torque friction in gearboxes and the pertinence of FTDs; section IV, the experimental setups developed and the procedures to obtain the FTD; section V, the experiments results and section VI, the discussion and future work.

\section{The Strain WAVE GeAR (HARMONIC Drive TyPe) AND ITS APPLICATION IN COLLABORATIVE ROBOTS}

\section{A. Harmonic Drive Operation}

Unlike a classical gear, the HD gearbox kinematic principle uses a continuous propagation of a strain wave thanks to the elastic properties of the chosen materials [4]. The three main components of a HD are: (1) the wave generator, (2) the flexspline and (3) the circular spline as depicted in Fig. 1. The wave generator is an elliptical ball bearing assembly that is inserted into the bore of the externally toothed flexspline. The elastic properties of the flexspline allow it to take on the elliptical shape of the wave generator. The outer teeth of the flexspline engage with the inner teeth of the crown along the major axis of the ellipse while they are disengaged along the minor axis. Hence there are many more engaged teeth than with a traditional gear. In a basic configuration, the wave generator induces the rotation of the flexspline in an opposite direction relative to the circular spline due to the difference in the number of teeth. This leads to the definition of its input/output velocity ratio (reduction ratio) formula. Depending on the choice of fixed and driven elements, various ratios and signs can be obtained.

\section{B. Harmonic Drive Drawbacks}

However, several drawbacks have been identified, such as some kinematic error [6], [7], hysteresis [8], [9], some inertia and a somewhat complex friction behavior [2], identified in [3] as the responsible for most of the energy loss having an important impact on the torque transmission. 


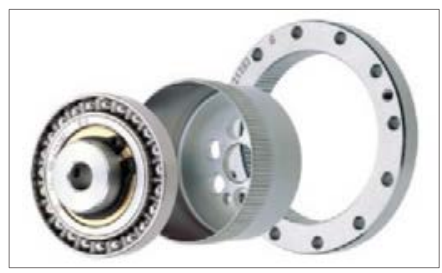

Figure 1. Harmonic Drive gearbox main components: 1) Wave generator, 2) flexspline and 3) circular spline [5].

\section{TORQUE FRICTION LAW}

\section{A. Friction Torque Model of Gearboxes}

Such models commonly take two cases into account: (i) the quasi-static case where the Coulomb's law of friction is applied as sliding contacts (or rolling contacts) [10], (ii) the dynamic case, for higher sliding speed, Stribeck effect is added to viscous friction to model speed influence. However, load influence is often neglected. The variation of friction as a function of contact load is rarely correctly modeled and this may be problematic when robots and mechanisms have large load variations. Thus, it becomes indispensable to consider the load (in addition to the speed) in the computation of the friction.

Numerous works have been published on the friction torque model of HD gearboxes [11], [12], [13], [14], [15] [16] considering friction as constant, while several friction models consider the friction as dependent of the load and the sense of movement [17], [18], [19], [20].

\section{B. Friction Torque Model Derived from Torque Transfer Ratio}

Inventor Walton Müsser [4] first proposed to compute the ratio of output/input torque under contact friction. He used 2 inclined planes in series, representing the effect of the elliptical ball bearing cam deforming the flexspline and a pair of engaged teeth. Using Coulomb's law, he assigned each contact a coefficient of kinematic (or dynamic) friction (rolling for the elliptical bearing and sliding for the pair of teeth). He then deduced an expression of the output/input ratio by multiplying the force transfer ratios of the two inclines. In fact, when using inclines, there are 2 distinct expressions of the torque transfer ratio depending on the direction of energy transfer associated to two torque transfer coefficients DIRECT and INDIRECT. The differences between the torque transfer slopes and the reduction slope gives two linear expressions of the torque friction in the HD gearbox. This method will be explained further when detailing the concept of FTD used in our study.

\section{Force Transfer Diagram (FTD)}

A FTD is a parametric representation of the equilibrium of a gearbox (or an actuator) submitted to an input and output torque, for various conditions of movement (speed and acceleration). In a broader sense, a FTD can be used to characterize the dynamic model of a gearbox or actuator. It can be directly identified for any type of mechanism by plotting a set of equilibrium points on a two-dimensional graph (Fig. 2).

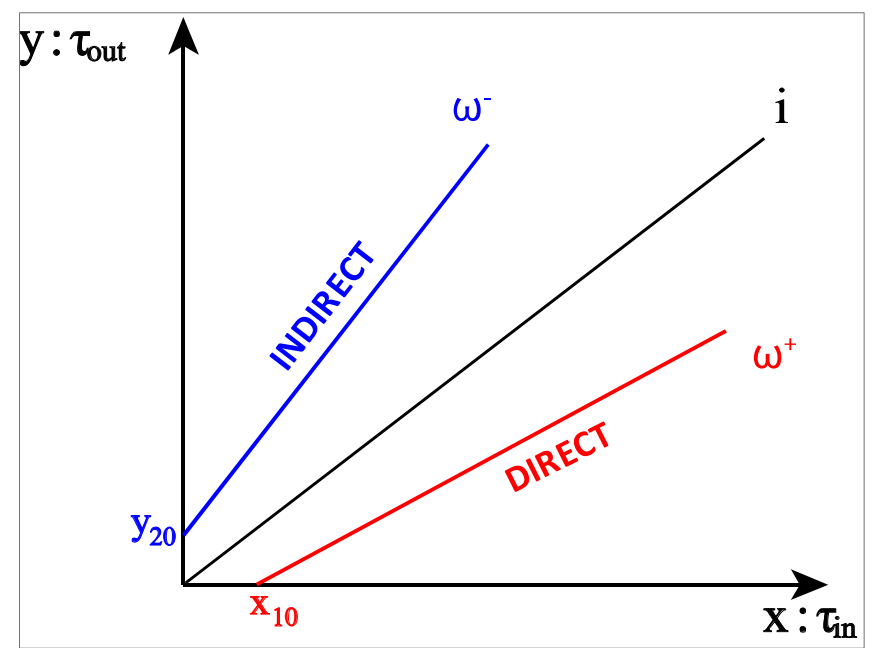

Figure 2. Force Transfer Diagram notional shape.

$\tau_{\text {in }}$ represents the input torque applied to the gearbox.

$\tau_{\text {out }}$ represents the output torque of the gearbox.

The black line $i$ (THEORETICAL) corresponds the reduction ratio of the gearbox i.e. the torque transfer law in the absence of friction.

The red line (at the right of $i$ ) represents the DIRECT direction (transmission of energy from the input to the output).

The blue line (at the left of $i$ ) represents the INDIRECT direction (transmission of energy from the output to the input [21]).

$\omega^{+}$and $\omega^{-}$represent the direction of rotation of the gearbox referring to the DIRECT and INDIRECT slopes.

$x_{10}$ and $y_{20}$ represent the DIRECT and INDIRECT thresholds.

The experience shows that in general the characteristics DIRECT and INDIRECT are not parallel to the reduction ratio (THEORETICAL) and that there are offset from the origin (thresholds).

The ratio (DIRECT slope/reduction slope) gives the DIRECT force transfer coefficient. The ratio (reduction slope/ INDIRECT slope) gives the INDIRECT force transfer coefficient. When the INDIRECT coefficient is positive, the system is reversible and irreversible when it is negative. When both coefficients are equal the mechanism is qualified as symmetrical and asymmetrical when they differ. A screw is potentially asymmetrical, excepted for a lead angle of $45^{\circ}$. With a spur gear, the coefficient of transfer deduced from the theoretical sliding formula of meshing teeth and the coefficient of sliding friction is equal for both sense meaning that a spur gear is symmetrical.

The efficiency can be defined as the ratio of output torque with friction/theoretical output torque only if it is positive and assuming an exact constant reduction ratio. Besides the existence of thresholds, force transfer coefficients should not be confused with efficiencies.

On any mechanical transmission, the friction is acting against the motoring effort whether it is applied at the input or output. This means that there are potentially two distinct friction torque laws DIRECT (motoring) and INDIRECT (regenerating) implying corresponding loss friction torques. 
Previous works [22], [21] have established that these laws can be deduced from the FTD of the gearbox. As shown on (Fig. 7), friction torque laws are obtained as the differences between DIRECT and INDIRECT characteristics and the reduction ratio slope.

\section{Identification of the FTD}

Parting from this principle, we designed 2 experimental setups to obtain the quasi-static equilibrium of the gearbox under various values of input/output constant torque and for each sense of motion. The interpolation of these plotted points enables the construction of the FTD (section IV).

\section{EXPERIMENTAL SETUPS}

We developed two setups to obtain the corresponding FTDs for each of the different HDs. Table 1 presents the specifications available of the tested HD, including the velocity ratio, rated torque, repeatable and momentary peak torque.

TABLE I. HARMONIC DRIVE SPECIFICATIONS

\begin{tabular}{|c|c|c|c|c|c|c|}
\hline Setup & $\begin{array}{c}\text { Harmonic } \\
\text { Drive }\end{array}$ & Size & $\begin{array}{c}\text { Vel. } \\
\text { ratio }\end{array}$ & $\begin{array}{c}\text { Rated } \\
\text { torque } \\
T_{N} \\
{[\mathrm{Nm}]}\end{array}$ & $\begin{array}{c}\text { Repeatable } \\
\text { peak } \\
\text { torque } \\
T_{R} \\
{[\mathrm{Nm}]}\end{array}$ & $\begin{array}{c}\text { Momentary } \\
\text { peak torque } \\
T_{M} \\
{[\mathrm{Nm}]}\end{array}$ \\
\hline 1 & $\begin{array}{c}\text { HFUC-20- } \\
2 \mathrm{UH}-100 \\
\text { (Cup type) }\end{array}$ & 20 & 100 & 40 & 82 & 147 \\
\hline 1 & $\begin{array}{c}\text { HFUS-20- } \\
2 \text { 2SO-100 } \\
\text { (Mushroom } \\
\text { type) }\end{array}$ & 20 & 100 & 40 & 82 & 147 \\
\hline $\begin{array}{c}\text { HDUR-32- } \\
\text { IH-120 } \\
\text { (Differential) }\end{array}$ & 32 & 120 & 137 & 353 & 686 \\
\hline
\end{tabular}

\section{A. Setup 1: Workbench}

We experimentally drew the transfer diagram in quasistatic conditions. We constructed a workbench in order to measure the torque values at the input and output for two different HD gearboxes: HFUC-20-2UH-100 and HFUS-202SO-100. This workbench (see Fig. 3 and 4) allows measuring the torques by adding weight at the input and output of the gearbox: it reproduces the effect of the torques (see section IV.C for the measurements procedures).

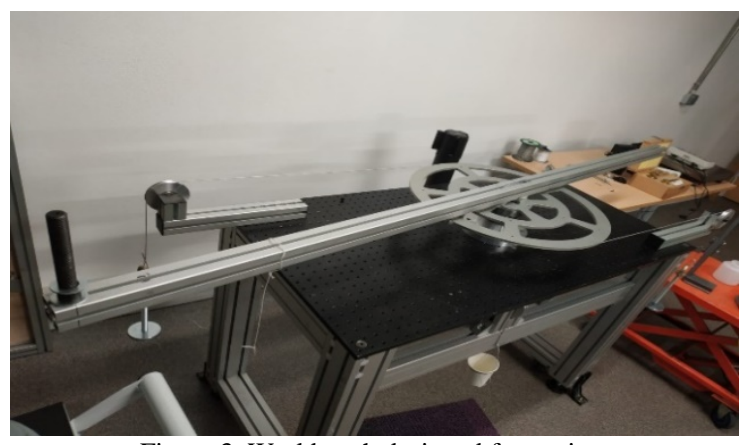

Figure 3. Workbench designed for testing.

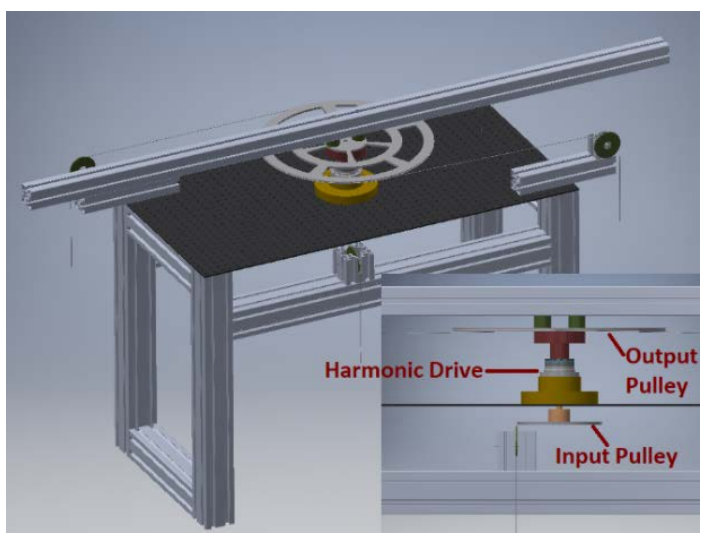

Figure 4. Isometric view of the workbench 3D CAD model.

In Fig. 4 we introduced one pulley with $r_{i n}=33 \mathrm{~mm}$ below the table to induce a torque at the input. We used another pulley with $r_{\text {out }}=250 \mathrm{~mm}$ above the HD in the output. On the later, we attached the cables at both extremities. The cables go in opposite directions to exert equal forces at both sides: it generates a "pure torque" at the output of the gearbox.

\section{B. Setup 2: Differential Harmonic Drive Joint-Link}

A second testbench was developed to test a differential HD gearbox (HDUR-32-IH-120) included in a special type of joint developed earlier at CEA. The HDUR principle is already described in the original patent of Walton Müsser dated from 1955 as a variant of the cup model. In this special joint, two units are symmetrically mounted in the branches of the fork articulation and both are driven by a unique shaft. We neglect here a potential slight preload in the mounting and its effect on the friction on each unit. Similarly, to Setup 1, we drew the transfer diagram in quasi-static conditions to determine the load-dependent friction performance, assuming that it is representative of a virtual gearbox that would have twice the capacity of each.

The joint schematics including two units of the differential HDUR gearbox is shown in Fig. 5 (the HDs appear in red).

Fig. 6 presents the Setup 2. With this configuration we were able to add weight at the input (directly from a pulley in the input axe joint) and at the output (at a given distance on the bar) to generate the input and output torques.

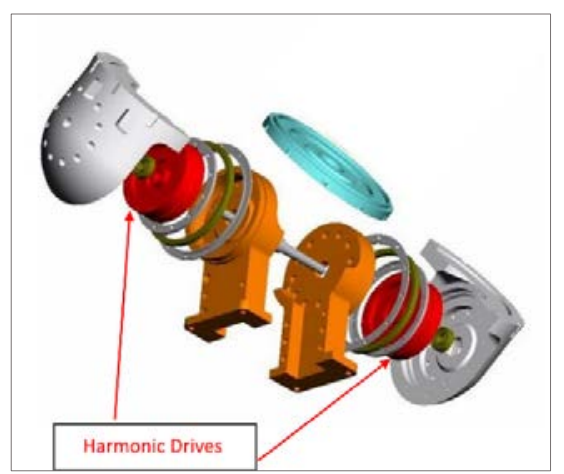

Figure 5. Fork joint arrangement using a pair of HDUR gearboxes working in parallel (earlier developed at CEA). 


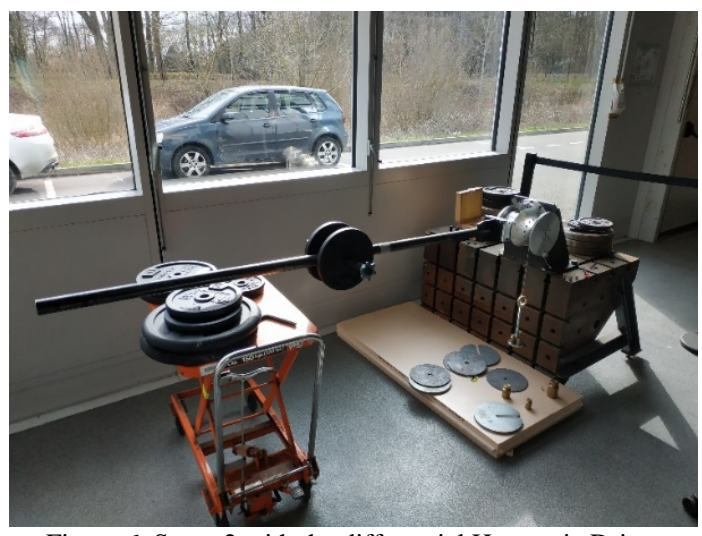

Figure 6. Setup 2 with the differential Harmonic Drive.

\section{Measurement Method}

As stated in IV.A, these setups allow performing measurements by adding weight at the input and output, and afterwards these weights are used to calculate the torque values. The material used for the measurements: calibrated weights and datasheets for computations.

There are 3 procedures to be executed:

a) INDIRECT threshold obtention:

Adding weight at the output without weight in the input until the system starts moving continuously.

b) DIRECT threshold obtention:

Adding weight at the input without weight in the output until it starts moving continuously.

c) DIRECT and INDIRECT weight values obtention at the input, at a given output weight:

1. Adding a known weight at the output.

2. For that known weight, weight is added at the Input until the system starts moving continuously and the value is registered (DIRECT input weight value).

3. The weight is to decrease at the Input until the Output starts moving in the other direction and this new value is registered (INDIRECT input weight value).

4. Repeat steps 1-3 by changing the weight at the output.

Equations (1) and (2) are used to calculate the torque values for the Setup 1.

$$
\begin{gathered}
\tau_{\text {in }}{ }^{\{D, I\}}=m_{\text {in }}{ }^{\{D, I\}} r_{\text {in }} g \\
\tau_{\text {out }}=m_{\text {out }} r_{\text {out }} g
\end{gathered}
$$

where:

$$
\begin{aligned}
& \boldsymbol{m}_{\boldsymbol{i n}}=\text { Input mass } \\
& \boldsymbol{m}_{\text {out }}=\text { Output mass } \\
& \boldsymbol{r}_{\boldsymbol{i n}}=\text { Radius of the Input pulley } \\
& \boldsymbol{r}_{\boldsymbol{o u t}}=\text { Radius of the Output pulley } \\
& \boldsymbol{g}=9.81 \mathrm{~m} / \mathrm{s}^{2}
\end{aligned}
$$

Equation's (1) superscript $\{D, I\}$ specifies whether if it is a value coming from a DIRECT measurement or an INDIRECT measurement, respectively.

Equation (3) is used instead of (1) when performing the procedure for Setup 2.

$$
\tau_{\text {out }}=m_{\text {out }} l_{\text {out }} g
$$

where:

$$
\boldsymbol{l}_{\text {out }}=\text { Distance to the center of mass }
$$

Fig. 7 depicts the friction torque derived laws present at a determined output load $\tau_{L O A D}$. Here $P_{1}$ and $P_{2}$ represent the DIRECT and INDIRECT measurements with coordinates $\left(x_{1}\right.$ , $\left.\tau_{L O A D}\right)$ and $\left(x_{2}, \tau_{L O A D}\right)$ obtained with (1) and (2) or (3); $x_{t h}$ is the ideal desired torque, obtained from the reduction ratio $i$ at the given $\tau_{L O A D}$.

The DIRECT friction torque (DFT) and INDIRECT friction torque (IFT) represent the frictions values existing in the gearbox depending on the direction of movement.

When the gearbox is motoring (4) shows that DFT is acting in the opposite direction of $x_{t h}$ which is why $x_{1}$ compensates this friction with respect to $i$.

Similarly, IFT is the friction at the gearbox when $\tau_{L O A D}$ is actuating in INDIRECT manner (the $\tau_{L O A D}$ regenerates towards the gearbox torque), this value can be reflected at the input by the Reflected INDIRECT friction torque (RIFT). In (5) can be seen that RIFT is reducing the input torque when the gearbox is in the regenerating direction.

$$
\begin{gathered}
x_{1}=x_{t h}+D F T \\
x_{t h}-R I F T=x_{2}
\end{gathered}
$$

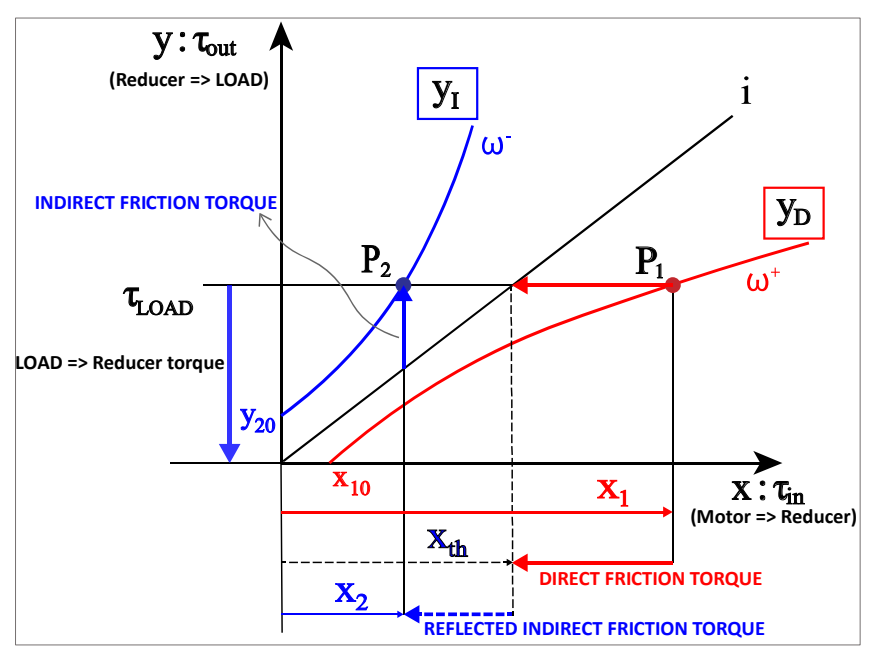

Figure 7. Friction torques laws derived from the FTD of a Harmonic Drive gearbox. 


\section{RESULtS}

We identified the load-dependent friction laws of three HD gearboxes by using the FTD.

\section{A. Load-Dependent Friction with HFUC}

Following the established procedure in section IV.C we obtained three data sets with the HFUC HD in order to test the repeatability. Fig. 8 shows input and output torques. We can observe that three measurements are such repeatable that points are almost overlaid.

We performed a second order polynomial curve fitting for the DIRECT (in red) and INDIRECT (in blue) curves.

As the load increase, the measurements continue to separate from the theoretical gearbox ratio (black line).

The variation of the 3 data sets is minimal which confirms its reproducibility, and a polynomial regression was fitted for each one of the curves with a coefficient of determination close to 1 .

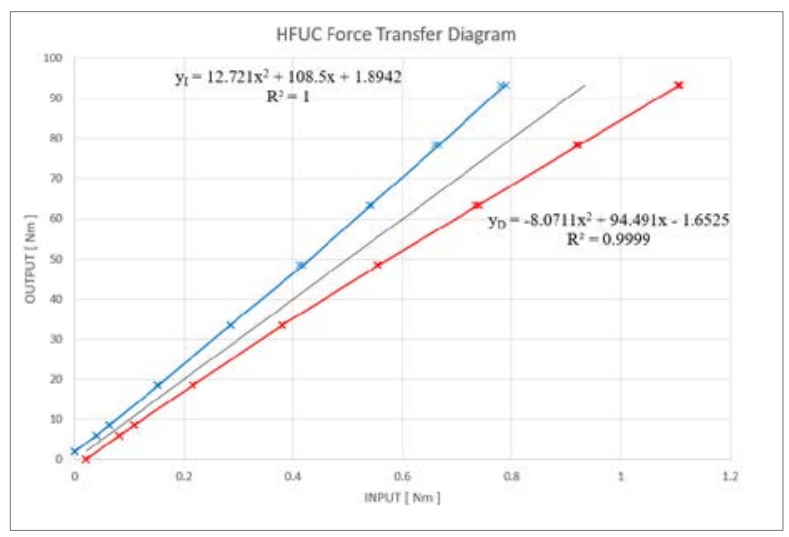

Figure 8. HFUC transfer diagram.

\section{B. Load-Dependent Friction with HFUS}

Similarly, for this second HD (HFUS), there were performed 3 data sets of measurements. The results are shown in Fig 9.

The DIRECT and INDIRECT curves behave in a similar manner as with the HFUC, we can perceive that they are actual curves and no lines with a simple slope.

Polynomial regressions were fitted, and their coefficient of determination are virtually 1 , indicating a confident fit.

If we compare Fig. 8 and 9, we can perceive that the later has slightly more variability in the last 3 measurements in the DIRECT curve, probably due to the difference in models, assembly, constraints and properties specifications.

\section{Load-Dependent Friction with HDUR}

Due to different composition and complexity of the arrangement in the differential HDUR joint, we expected it to perform in a similar curved manner as shown in previous tests with Setup 1.

After just the first 3-4 measurements we could deduce that the behavior was similar and even more palpable: the system behavior would diverge in a curved manner, both in the
DIRECT and INDIRECT measurements. This can be seen in Fig. 10.

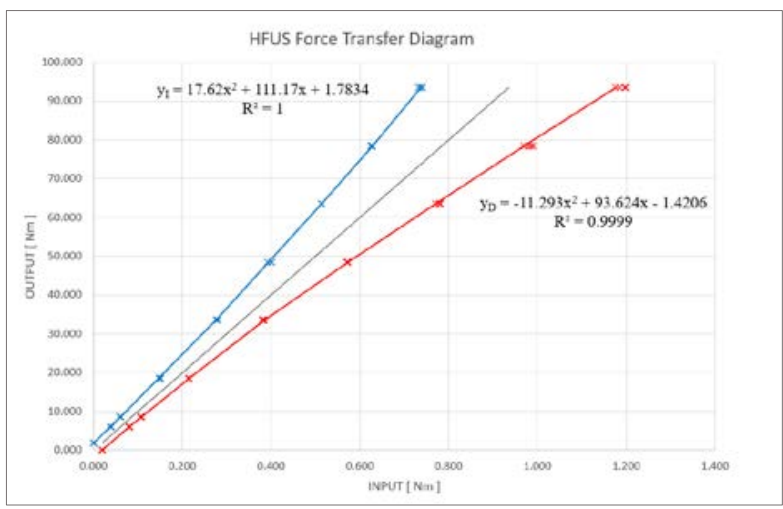

Figure 9. HFUS transfer diagram.

Analogously, two second order regressions have been obtained to describe the DIRECT and INDIRECT curves with a coefficient of determination close to 1 .

In Fig. 10 the curvature of transfer function is abrupter, compared to Fig. 8 and 9. This may be explained by the difference of construction because with the differential principle used, the strain gear is not a single unit. Instead, it is composed of a cylindrical toothed portion engaging in a ring that has the same number of teeth. During operation, even if the relative angular motion of these two parts is null, there are some torque losses induced by the radial movement of the teeth.

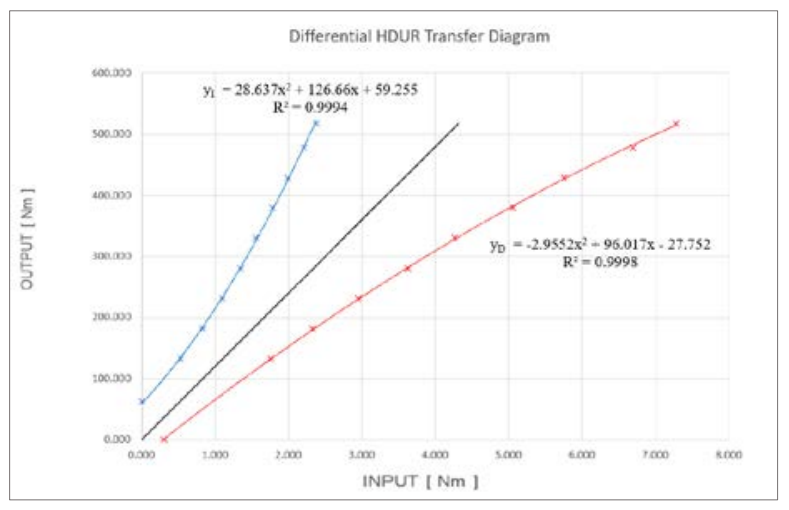

Figure 10. Differential HDUR transfer diagram.

\section{DISCUSSION}

This paper has presented new parabolic friction torque laws for HD gearboxes thanks to the identification of their empirical Force Transfer Diagrams. The simplicity of the quasi-static method used has however produced highly reproductible results and we consider it as reliable.

These torque friction models will be used to improve the linearity of joint torque control at low speed by compensating the electromagnetic motor torque (current). In the context of collaborative robotics, we are expecting a more sensitive detection of undesired contacts and a reduced resistance when operating a transparent control mode and this, whatever the load and the sense of movement. 
Further work would be necessary to complete the friction torque model by studying the effect of speed and its eventual coupling. This testbench should be modified to allow studying the effect of speed independently to the applied torque.

\section{ACKNOWLEDGMENT}

We acknowledge support from Commissariat à l'énergie atomique et aux énergies alternatives (FR), Instituto de Innovación y Transferencia de Tecnología (N.L., MX) and Consejo Nacional de Ciencia y Tecnología (MX).

\section{REFERENCES}

[1] N. M. Kircanski and A. A. Goldenberg, "An experimental study of nonlinear stiffness, hysteresis and friction effects in robot joints with Harmonic Drives and torque sensors," The International Journal of Robotics Research, vol. 16, p. 214-239, April 1997. DOI: $10.1177 / 027836499701600207$

[2] J. P. Hauschild, G. R. Heppler and J. J. McPhee, "Friction compensation of Harmonic Drive actuators," 2004.

[3] C. Preissner, T. J. Royston and D. Shu, "A high-fidelity Harmonic Drive model," Journal of Dynamic Systems, Measurement, and Control, vol. 134, p. 011002, January 2012. DOI: 10.1115/1.4005041

[4] W. Müsser, "Strain wave gearing". Patent 2906 143, September 1959.

[5] "Harmonic Drive main components," [Online]. Available: https://www.harmonicdrive.net/technology. [Accessed 0701 2021].

[6] F. H. Ghorbel, P. S. Gandhi and F. Alpeter, "On the kinematic error in Harmonic Drive gears," Journal of Mechanical Design, vol. 123, p. 9097, March 2001. DOI: 10.1115/1.1334379

[7] P. S. Gandhi, F. H. Ghorbel and J. Dabney, "Modeling, identification, and compensation of friction in harmonic drives," in Proceedings of the 41st IEEE Conference on Decision and Control, 2002., Las Vegas, NV, USA, 2002.

[8] P. S. Gandhi and F. H. Ghorbel, "Control of hysteresis and kinematic error nonlinearities in harmonic drives for high speed precision control applications," in Proceedings of the 2004 American Control Conference, Boston, 2004.

[9] M. Yamamoto, M. Iwasaki, H. Hirai, Y. Okitsu, K. Sasaki and T. Yajima, "Modeling and compensation for angular transmission error in harmonic drive gearings," IEEJ Transactions on Electrical and Electronic Engineering, vol. 4, p. 158-165, March 2009.

[10] D. Spenlé and R. Gourhant, "Guide du calcul en mécanique," in Hachette Technique, 2007.

[11] A. Tadayoni, W.-F. Xie and B. W. Gordon, "Adaptive control of harmonic drive with parameter varying friction using structurally dynamic wavelet network," International Journal of Control, Automation and Systems, vol. 9, p. 50-59, February 2011. DOI: 10.1007/s12555-011-0107-5

[12] Z. Shi, Y. Li and G. Liu, "Adaptive torque estimation of robot joint with harmonic drive transmission," Mechanical Systems and Signal Processing, vol. 96, p. 1-15, November 2017.

[13] D. Ma, S. Yan, Z. Yin and Y. Yang, "Investigation of the friction behavior of harmonic drive gears at low speed operation," in 2018 IEEE International Conference on Mechatronics and Automation (ICMA), Changchun, 2018.

[14] C. Zou, T. Tao, G. Jiang, X. Mei and J. Wu, "A harmonic drive model considering geometry and internal interaction," Proceedings of the Institution of Mechanical Engineers, Part C: Journal of Mechanical Engineering Science, vol. 231, p. 728-743, February 2017. DOI: $10.1177 / 0954406215621097$

[15] B. Han, J. Ma and H. Li, "Research on nonlinear friction compensation of harmonic drive in gimbal servo-system of DGCMG," International Journal of Control, Automation and Systems, vol. 14, p. 779-786, June 2016. DOI: $10.1007 / \mathrm{s} 12555-014-0430-8$

[16] H. Liao, S. Fan and D. Fan, "Friction compensation of harmonic gear based on location relationship," Proceedings of the Institution of Mechanical Engineers, Part I: Journal of Systems and Control Engineering, vol. 230, p. 695-705, September 2016. DOI: 10.1177/0959651816650083

[17] G. Abba and P. Sardain, "Modeling of frictions in the trnsmission elements of a robot axis for its identification," IFAC Proceedings Volumes, vol. 38, p. 7-12, 2005.

[18] P. Hamon, M. Gautier and P. Garrec, "Dynamic identification of robots with a dry friction model depending on load and velocity," in 2010 IEEE/RSJ International Conference on Intelligent Robots and Systems, Taipei, 2010.

[19] Pauline Hamon, "Dynamic modeling and identification of robots with a dry friction model depending on load and velocity.," 2011.

[20] N. Kammerer and P. Garrec, "Dry friction modeling in dynamic identification for robot manipulators: Theory and experiments," in 2013 IEEE International Conference on Mechatronics (ICM), Vicenza, 2013.

[21] P. Garrec, F. Geffard, O. David, F.-X. Russotto, Y. Measson and Y. Perrot, "TELEROBOTICS RESEARCH AND DEVELOPMENT AT CEA LIST," in ANS EPRRSD, Knoxville, 2011.

[22] P. Garrec, J.-P. Friconneau and F. Louveaux, "Virtuose 6D: A new force-control master arm using innovative ball-screw actuators," in ISR 2004 : 35th International Symposium on Robotics, Villepinte, ParisNord, France, 2004. 